\title{
Crack-Tip Stress Analysis at a Bi-Material Interface by Photoelastic, Isopachic and FEA
}

\author{
George A. Papadopoulos ${ }^{1 *}$, Elen B. Bouloukou ${ }^{1}$, Elen G. Papadopoulou ${ }^{2}$ \\ ${ }^{1}$ National Technical University of Athens, Department of Engineering Science, Section of Mechanics, Zografou campus, Athens, \\ Greece; ${ }^{2}$ National Technical University of Athens, Department of Mining Engineering and Metallurgy, Laboratory of physical Met- \\ allurgy, Athens, Greece. \\ Email: *gpad@central.ntua.gr, papadel@central.ntua.gr
}

Received April 30 ${ }^{\text {th }}$, 2011; revised May 25 ${ }^{\text {th }}$, 2011; accepted June $2^{\text {nd }}, 2011$.

\begin{abstract}
The paper investigates the stress state at the bi-material interface crack-tip by the Photoelastic and Isopachic methods and the Finite Element Analysis (FEA). The principal stresses at the bi-material interface crack-tip are theoretically determined using the combination photoelastic and isopachic fringes. The size and the shape of crack-tip isochromatic and isopachic fringes, at a bi-material interface under static load, are studied. When the crack-tip, which is perpendicular to interface, is placed at the interface of the bi-material, the isochromatic and the isopachic fringes depend on the properties of the two materials. Thus, the isochromatic and the isopachic fringes are divided into two branches, which present a jump of values at the interface. The size of the two branches mainly depends on the elastic modulus and the Poisson's ratio of the two materials. From the combination of the isochromatic and the isopachic fringes, the principal stresses $\sigma_{1}$ and $\sigma_{2}$ can be estimated and the contour curves around the crack-tip can be plotted. For the FEA analysis, the program ANSYS 11.0 was used. The bi-material cracked plates were made from Lexan (BCBA) and Plexiglas (PMMA).
\end{abstract}

Keywords: Crack, Bi-Material, Photoelasticity, Isochromatic, Isopachic, FEA

\section{Introduction}

The study of the behaviour of a transverse crack propagating through the mesophase of composites has become a subject of great interest. The problem of crack propagation in a duplex plate was studied by Williams et al. [1-5] and later was approached by Dally and Kobayashi [6] by means of dynamic photoelasticity. Theocaris et al. [7-9] have studied the influence of both the mesophase and the material characteristics of either phase, in biphase plates consisting of different materials, on the stress distribution around the crack tip. They have extended their study to the magnitude and the variation of the crack propagation velocities during fracture in duplex plates under dynamic loading [10]. Also, Theocaris et al. [11,12] have studied the influence of the hard or soft fiber and the mesophase layers in a soft-hard-soft or hard-soft-hard combination of biphase plate subjected to a dynamic tensile load, on the fracture mode and bifurcation process in both phases. Also, theoretical studies on this subject were carried out by Gdoutos et al. [13-15] and Theotokoglou et al. [16,17]. The study of the size and the shape of crack-tip caustics at a bi-material interface was carried out by Papadopoulos [18]. Sadowski et al. [19,20] have studied the bi-material interface problem for ceramic materials by FEA. In the present paper, we estimate the principal stresses and its contour curves at the bi-material interface crack-tip from the combination of the isochromatic and the isopachic fringes and the FEA.

\section{Crack-Tip Stresses at the Interface}

Two plates of module $E_{1}$ and $E_{2}$ and Poisson's ratio $v_{1}$ and $v_{2}$ are perfectly bonded along their common interface (Figure 1). In plate (1) there is a crack perpendicular to the interface. The crack-tip is placed exactly at the interface of the two plates. The Airy stress function $X(r, \theta)$ for this problem, used by Zak and Williams [5], is:

$$
X(r, \theta)=r^{\lambda+1} F(\theta)
$$

with:

$$
\begin{gathered}
F(\theta)=\alpha \sin (\lambda+1) \theta+b \cos (\lambda+1) \theta+ \\
c \sin (\lambda-1) \theta+d \cos (\lambda-1) \theta
\end{gathered}
$$


where $\alpha, b, c, d$ are constants and $\lambda$ takes values between 0 and 1 , which is depended on the ratio $E_{12}=E_{1} / E_{2}$ of the two plates moduli [18].

From the stress function (1) the polar stresses at the crack-tip are taken:

$$
\begin{gathered}
\sigma_{r}=-\lambda r^{\lambda-1}\left[\begin{array}{l}
\alpha(\lambda+1)|\sin (\lambda+1) \theta|+ \\
b(\lambda+1)|\cos (\lambda+1) \theta| \\
+c(\lambda-3)|\sin (\lambda-1) \theta|+ \\
d(\lambda-3)|\cos (\lambda-1) \theta|
\end{array}\right] \\
\sigma_{\theta}=\lambda(\lambda+1) r^{\lambda-1}\left[\begin{array}{l}
\alpha|\sin (\lambda+1) \theta|+ \\
b|\cos (\lambda+1) \theta|+ \\
c|\sin (\lambda-1) \theta|+ \\
d|\cos (\lambda-1) \theta|
\end{array}\right] \\
\tau_{r \theta}=-\lambda r^{\lambda-1}\left[\begin{array}{l}
\alpha(\lambda+1)|\cos (\lambda+1) \theta|- \\
b(\lambda+1)|\sin (\lambda+1) \theta|+ \\
c(\lambda-1)|\cos (\lambda-1) \theta|- \\
d(\lambda-1)|\sin (\lambda-1) \theta|
\end{array}\right]
\end{gathered}
$$

\section{Specimens}

Specimens were made from Plexiglas (PMMA) with Poisson ratio $v=0.34$ and Elasticity modulus $E=3.4$ GPa and Lexan (BCBA) with $v=0.36$ and $E=2.8 \mathrm{GPa}$, subjected to static uniaxial tension. The specimens thickness was $t=0.003 \mathrm{~m}$. The crack width was $0.3 \mathrm{~mm}$ with a sharp tip at the interface (Figure 1).

\section{Theory of Photoelasticity}

Isochromatic fringes are loci of points with the same

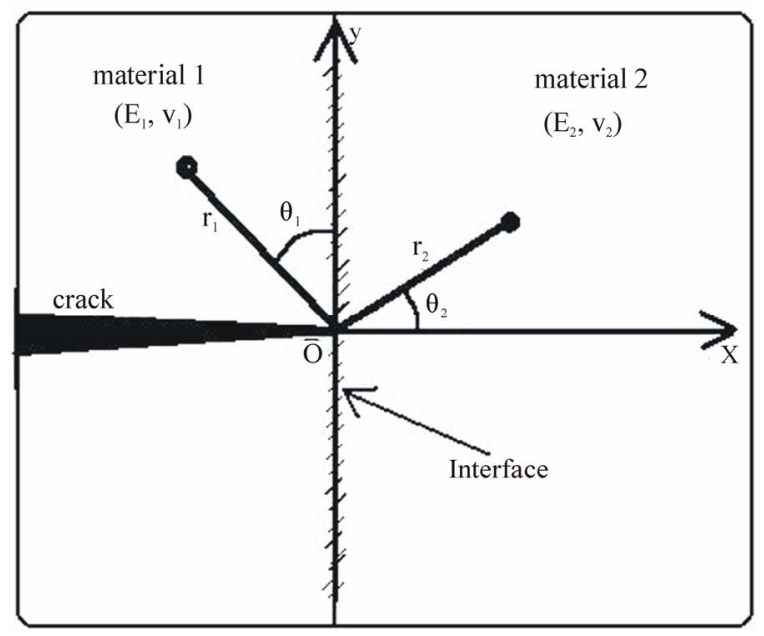

Figure 1. Geometry of bi-material plate value for the difference of the principal stresses or the maximum shear stress. According to the stress optical law, the difference in the principal stresses is given by Frocht [21]:

$$
\sigma_{1}-\sigma_{2}=2 \tau^{\max }=\frac{N_{c} f_{c}}{t}
$$

where $N_{c}$ is the isochromatic fringe order, $t$ is the thickness of the plate and $f_{c}$ is the material fringe value or stress-optical constant.

From equations (3)-(6) is obtained:

$$
r=\left\{\frac{N_{c}\left(f_{c}\right)_{1,2}}{\left[\left[\left(1-\lambda^{2}\right) F(\theta)+F^{\prime \prime}(\theta)\right]^{2}+4 \lambda^{2}\left(F^{\prime}(\theta)\right)^{2}\right]^{1 / 2} t}\right\}^{\frac{1}{\lambda-1}}
$$

The relation between the stress-optical constants of the materials 1 and 2 is:

$$
\left(f_{c}\right)_{2}=\frac{1}{E_{12}} \frac{v_{1}}{v_{2}}\left(f_{c}\right)_{1}
$$

where $E_{12}=E_{1} / E_{2}$ is the ratio of the elastic modulii and $v_{1}, v_{2}$ are the Poisson's ratio of the two materials.

\section{Theory of Isopachic Fringes}

Isopachics fringes are loci of points with the same value for the sum of the principal stresses. The fringe order $N_{p}$ of isopachic is related to the sum of the principal stresses by:

$$
\sigma_{1}+\sigma_{2}=\sigma_{r}+\sigma_{\theta}=\frac{N_{p} f_{p}}{t}
$$

where $N_{p}$ is the order of isopachics, $\mathrm{t}$ is the thickness of the plate and $f_{p}$ is the isopachic fringe constant.

The sum of the stresses (equations (3) and (4)) is:

$$
\sigma_{1}+\sigma_{2}=\sigma_{r}+\sigma_{\theta}=r^{\lambda-1}\left[(\lambda+1)^{2} F(\theta)+F^{\prime \prime}(\theta)\right]
$$

From equations (9) and (10) is obtained:

$$
r=\left\{\frac{1}{(\lambda+1)^{2} F(\theta)+F^{\prime \prime}(\theta)} \frac{N_{p}\left(f_{p}\right)_{1,2}}{t}\right\}^{\frac{1}{\lambda-1}}
$$

with:

$$
\left(f_{p}\right)_{2}=\frac{1}{E_{12}} \frac{v_{1}}{v_{2}}\left(f_{p}\right)_{1}
$$

where $\left(f_{p}\right)_{1,2}$ are the isopachic fringe constants of the materials 1 and 2 of the bi-material plate, respectively.

\section{Principal Stresses Estimation from the Isochromatic and Isopachic Fringes}

The principal stresses can be estimated from the system 
of isochromatic and isopachic fringes (Eqs (6), (9)). The solution of the system is valid at the cross points of the isochromatic and isopachic fringes (Figure 2). Figure 2 presents the overlapping of isochromatic and isopachic fringes by Eqs (7) and (11), for Lexan 1-Plexiglas 2 bi-material plate with $E_{12}=0.82353, v_{1}=0.36, v_{2}=0.34$, $\lambda=0.5192, t=0.003$ and $d_{2}=1\left(d_{2}\right.$ is an arbitrary constant which represents the tensile load of the plate. At the cross points of the fringes the principal stresses can be calculated by the Eqs (6) and (9).

From the solution of the equations (6) and (9) system, the principal stresses are obtained:

$$
\begin{aligned}
\sigma_{1}= & \frac{\sigma_{r}+\sigma_{\theta}}{2}+\frac{1}{2} \sqrt{\left(\sigma_{r}-\sigma_{\theta}\right)^{2}+4 \tau_{r \theta}^{2}}= \\
& \frac{N_{p}\left(f_{p}\right)_{1,2}+N_{c}\left(f_{c}\right)_{1,2}}{2 t} \\
\sigma_{2}= & \frac{\sigma_{r}+\sigma_{\theta}}{2}-\frac{1}{2} \sqrt{\left(\sigma_{r}-\sigma_{\theta}\right)^{2}+4 \tau_{r \theta}^{2}}= \\
& \frac{N_{p}\left(f_{p}\right)_{1,2}-N_{c}\left(f_{c}\right)_{1,2}}{2 t}
\end{aligned}
$$

By substituting the stresses from the Eqs (3)-(5) into Eqs (13), (14) the contour curves of the principal stresses, around the crack-tip, are obtained:

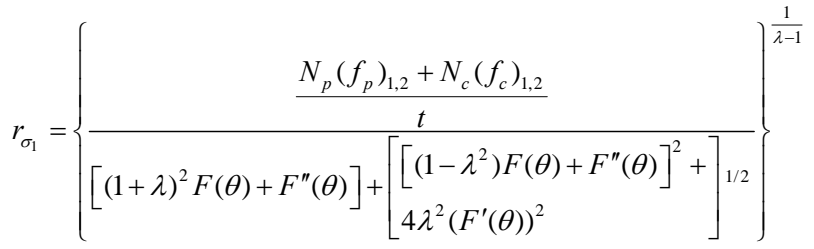

$$
r_{\sigma_{2}}=\left\{\frac{\frac{N_{p}\left(f_{p}\right)_{1,2}-N_{c}\left(f_{c}\right)_{1,2}}{t}}{\left[(1+\lambda)^{2} F(\theta)+F^{\prime \prime}(\theta)\right]-\left[\begin{array}{l}
\left.\left[\left(1-\lambda^{2}\right) F(\theta)+F^{\prime \prime}(\theta)\right]^{2}+\right] \\
4 \lambda^{2}\left(F^{\prime}(\theta)\right)^{2}
\end{array}\right]}\right\}^{\frac{1}{\lambda-1}}
$$

Figure 3 presents the contour curves of the principal stresses $\sigma_{1}$ and $\sigma_{2}$ around the crack-tip for Lexan 1-Plexiglas 2 bi-material plate with $E_{12}=0.82353, v_{1}=$ $0.36, v_{2}=0.34, \lambda=0.5192, d_{2}=1$ and $t=0.003$ for (a) isopachic fringe order $N_{p=1}$ and isochromatic fringe orders $N_{c}=3,4$ and (b) $N_{p=5}$ and $N_{c}=3,4$.

\section{Finite Element Analysis (FEA)}

The program ANSYS 11 is used in the finite element analysis (FEA) modeling. The mesh is generated using triangular elements 8-node 82 for the crack and the crack-tip of the model (Figure 4(a)).

The elements have the material properties for Lexan

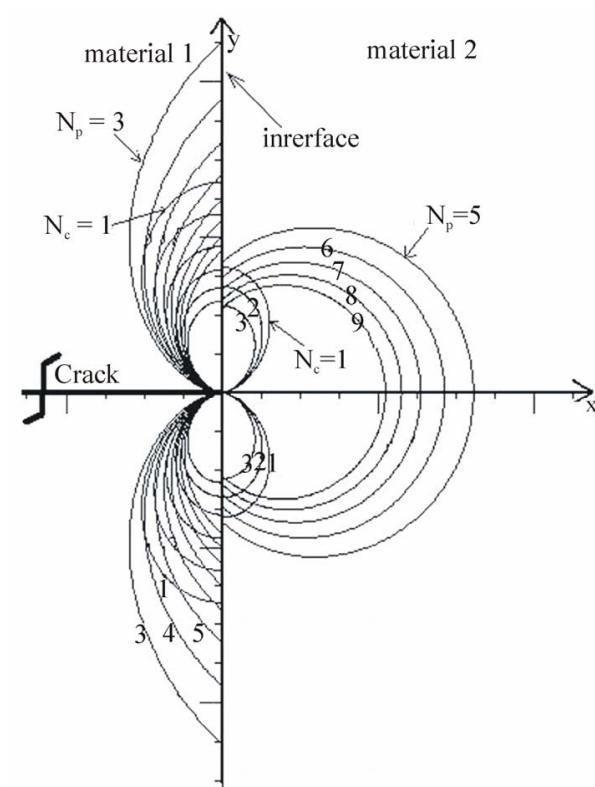

Figure 2. Theoretically overlapping of Isochromatic $\left(N_{c}\right)$ and Isopachic $\left(N_{p}\right)$ fringes.

$E=2.8 \mathrm{GPa}$ and $v=0.36$ and for Plexiglas $E=3.4 \mathrm{GPa}$ $\left(E_{12}=0.82353\right)$ and $v=0.34$. Figure 4(b) shows the mesh at the crack-tip that had been used in the analysis. Figure 4(c) shows the FEA model mesh for the crack and the interface of bi-material plate. For the calculation of the stresses and its contour curves at the bi-material interface crack-tip, with Plexiglas as material 1 and Lexan as material 2 or with Lexan as material 1 and Plexiglas as material 2 (Figure 1), a tensile load of $100 \mathrm{~N} / \mathrm{m}$ was applied.

Figure 5 shows the contour curves of principal stress $\sigma_{I}(\mathrm{~Pa})$ at the bi-material interface crack-tip for Plexiglas-Lexan bi-material plate.

Figure 6 shows the contour curves of principal stress $\sigma_{2}(\mathrm{~Pa})$ at the bi-material interface crack-tip for Plexiglas-Lexan bi-material plate.

Figure 7 shows the contour curves of principal stress $\sigma_{l}(\mathrm{~Pa})$ at the bi-material interface crack-tip for Lexan-Plexiglas bi-material plate.

Figure 8 shows the contour curves of principal stress $\sigma_{2}(\mathrm{~Pa})$ at the bi-material interface crack-tip for LexanPlexiglas bi-material plate.

The stresses variation in the direction of $45^{\circ}$ relative to crack direction are presented in next figures. Figure 9 shows the variation of principal stress $\sigma_{l}(\mathrm{~Pa})$ and Figure $\mathbf{1 0}$ shows the variation of principal stress $\sigma_{2}(\mathrm{~Pa})$ at the bi-material crack-tip.

\section{Results and Discussion}

From Figure 3 it is observed that the principal stresses $\sigma_{l}$ and $\sigma_{2}$ are rapidly increased approaching to the 


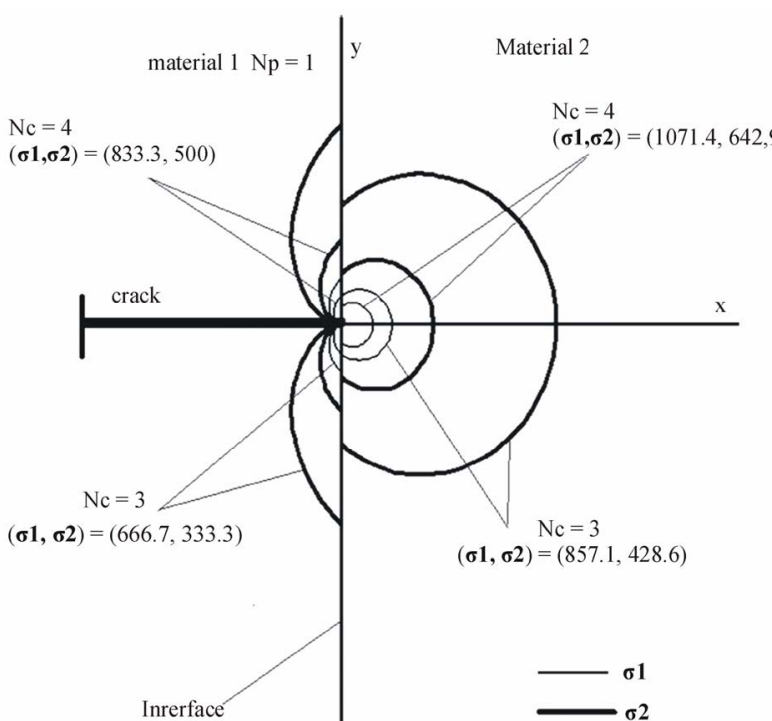

(a)

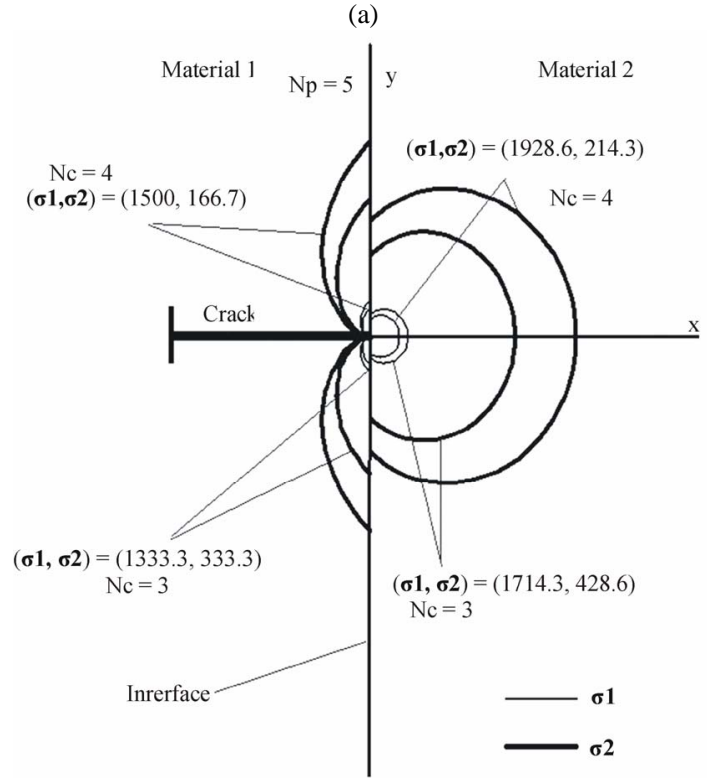

(b)

Figure 3. Contour curves of principal stresses around the crack-tip for (a) $N_{p}=1$ and $N_{c}=\mathbf{3 , 4}$ and (b) $N_{p}=\mathbf{5}$ and $N_{c}=\mathbf{3 , 4}$.

crack-tip.

For isopachic fringe order $N_{p}=1$ (Figure 3(a)) and for isochromatic fringe orders $N_{c}=3$ and 4 the principal stresses in material 2 (Plexiglas) are $\sigma_{1}=857.1 \mathrm{~Pa}$ and $1071.4 \mathrm{~Pa}$ and $\sigma_{2}=428.6 \mathrm{~Pa}$ and $642.9 \mathrm{~Pa}$, respectively. While, in material 1 (Lexan) the principal stresses are $\sigma_{1}=666.7 \mathrm{~Pa}$ and $833.3 \mathrm{~Pa}$ and $\sigma_{2}=333.3 \mathrm{~Pa}$ and $500 \mathrm{~Pa}$, respectively. For isopachic fringe order $N_{p}=5$ (Figure 3(b)), closer to the crack-tip than in state of Figure 3(a), and for isochromatic fringe orders $N_{c}=3$ and 4 the principal stresses in material 2 (Plexiglas) are

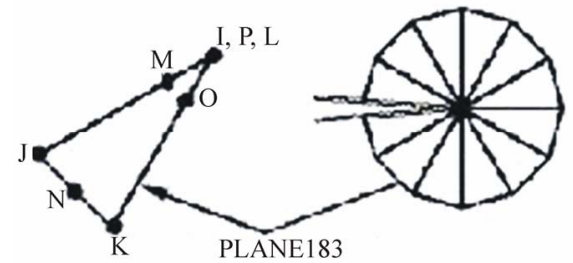

(a)

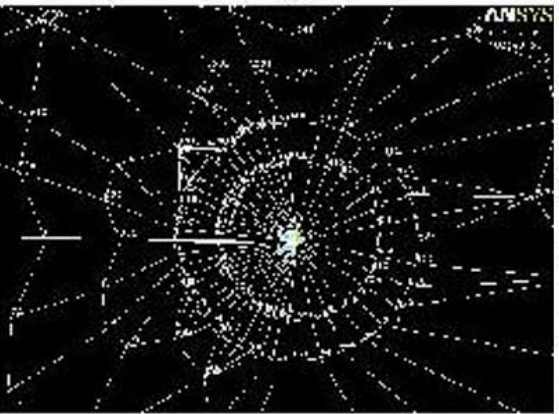

(b) (c)

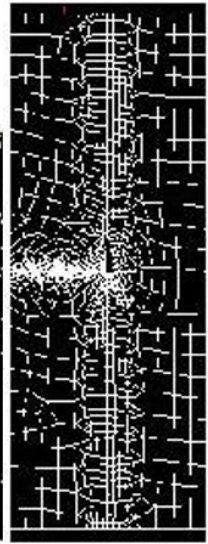

Figure 4. (a) Element 8-node 82, (b) FEA mesh at the crack tip, (c) Model FEA mesh.

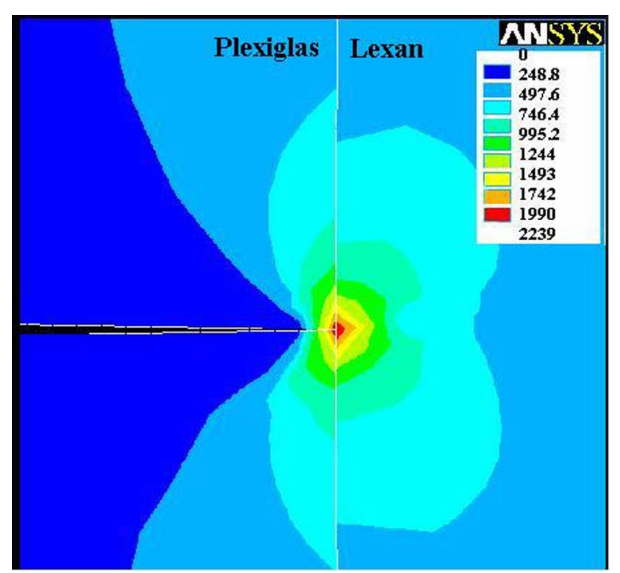

Figure 5. Contour of principal stress $\sigma_{1}(\mathrm{~Pa})$ at the bi-material interface crack-tip tip for Plexiglas-Lexan bi-material plate.

$\sigma_{1}=1714.3 \mathrm{~Pa}$ and $1928.6 \mathrm{~Pa}$ and $\sigma_{2}=428.6 \mathrm{~Pa}$ and 214.3Pa , respectively. While, in material 1 (Lexan) the principal stresses are $\sigma_{1}=1333.3 \mathrm{~Pa}$ and $1500 \mathrm{~Pa}$ and $\sigma_{2}=333.3 \mathrm{~Pa}$ and $166.7 \mathrm{~Pa}$, respectively. At the interface a jump of principal stresses values is observed because of the difference constants of two materials. So, from the experimental combination of the isochromatic and isopachic fringes the contour curves of principal stresses around the crack-tip can taken.

Applying the FEA, the contour curves of principal stresses around the crack-tip can theoretically taken. 


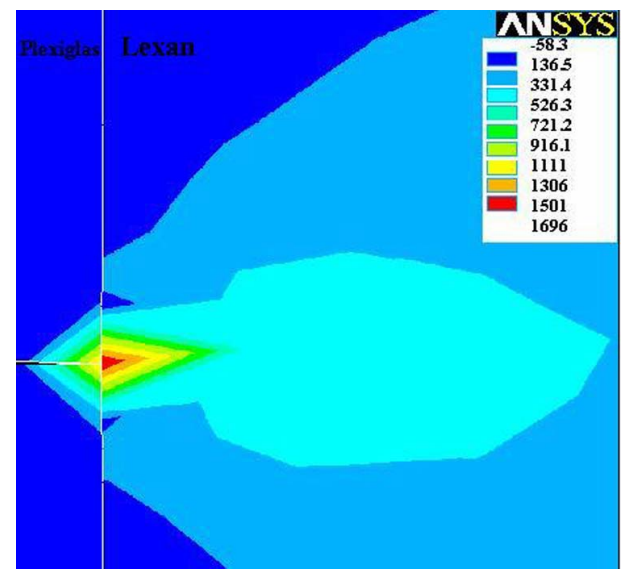

Figure 6. Contour of principal stress $\sigma_{2}(\mathrm{~Pa})$ at the bi-material interface crack-tip tip for Plexiglas-Lexan bi-material plate.

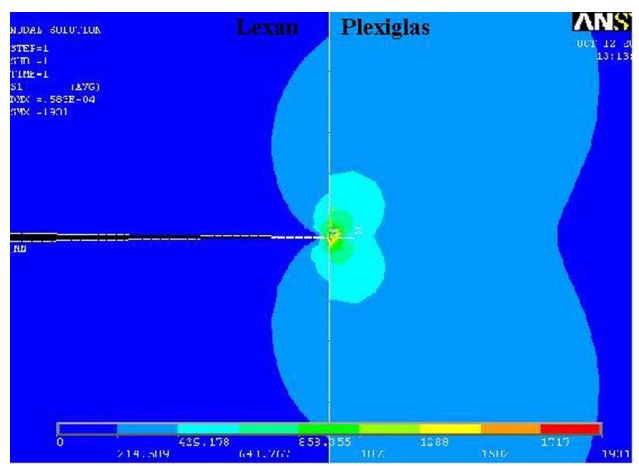

Figure 7. Contour of principal stress $\sigma_{1}(\mathrm{~Pa})$ at the bi-material interface crack-tip tip for Lexan-Plexiglas bi-material plate.

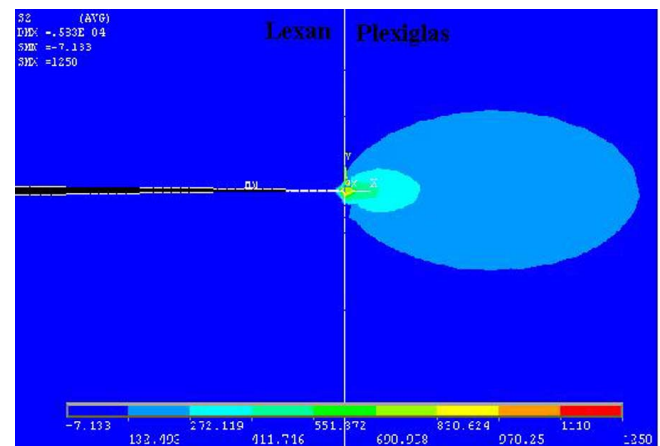

Figure 8. Contour of principal stress $\sigma_{2}(\mathrm{~Pa})$ at the bi-material interface crack-tip for Lexan-Plexiglas bi-material plate.

From Figures 5-8 it is observed that the contour curves of principal stresses are zones with a average values of principal stresses. Approaching the crack-tip, the principal stresses $\sigma_{1}$ and $\sigma_{2}$ are rapidly increased. The variation of the average values of principal stresses $\sigma_{1}$ and $\sigma_{2}$ in front of the crack-tip in the direction of $45^{\circ}$ relative to the crack-axis are presented in Figures 9 and 10, respectively. Figure 11 presents the experimentally overlapping of isochromatic and isopachic fringes for $E_{12}=1$ (one material, Lexan). At the cross points of the fringes the principal stresses can be calculated by the Eqs (6) and (9). Also, at crack tip the caustic was taken from which the stress intensity factor $\mathrm{K}_{\mathrm{I}}$ can be calculated [22].

\section{Conclusions}

According to the above study is concluded that the distribution of the principal stresses close and far from the crack-tip can be experimentally considered by the methods of photoelasticity and isopachics. Also, the contour curves of principal stresses can be experimentally plotted

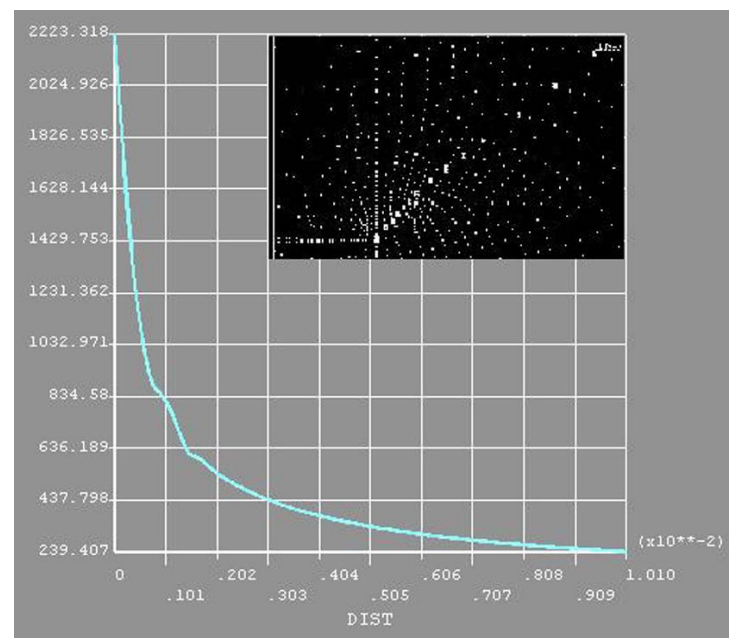

Figure 9. The variation of principal stress $\sigma_{1}(\mathrm{~Pa})$ in the direction of $45^{\circ}$ relative to crack direction (inset photo) at the bi-material interface crack-tip for Plexiglas-Lexan bi-material plate.

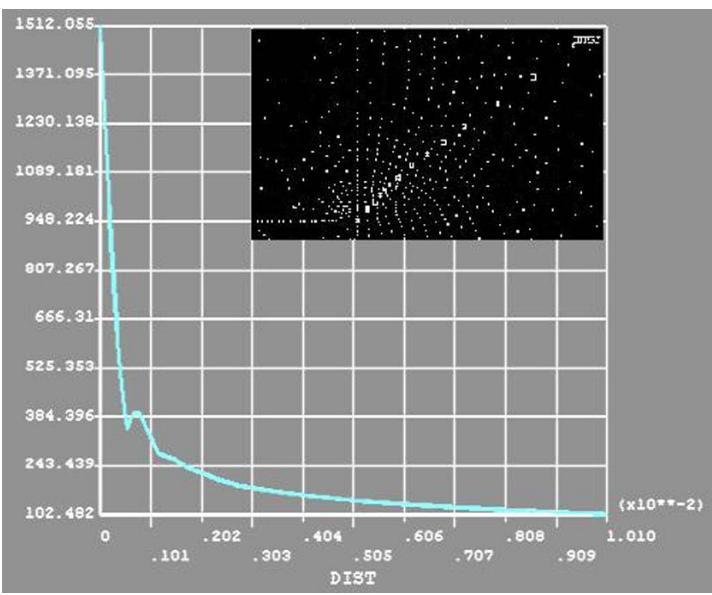

Figure 10. The variation of principal stress $\sigma_{2}(\mathrm{~Pa})$ in the direction of $45^{\circ}$ relative to crack direction (inset photo) at the bi-material interface crack-tip for Plexiglas-Lexan bi-material plate. 


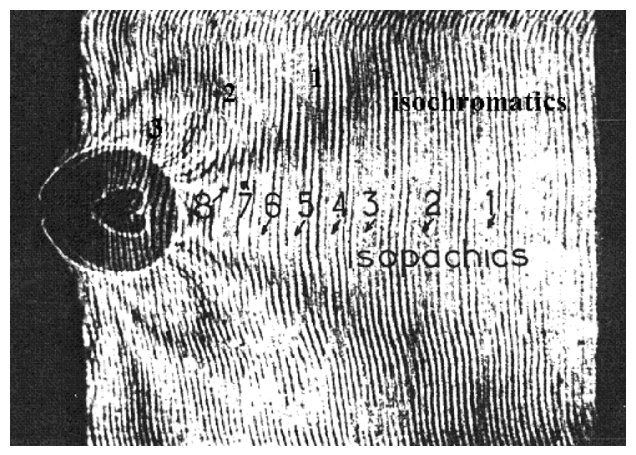

Figure 11. Experimentally overlapping Isochromatic and Isopachic fringes at the crack tip for one material (Lexan).

around the crack-tip at the interface of the bi-material from the overlapping of the isochromatic and isopachic fringes.

From the FEA analysis is concluded that: (a) The exactly contour curves of principal stresses can be theoretically estimated. (b) From the contour curves of stresses the variation of the principal stresses can be calculated in difference directions in front of bi-material crack-tip.

\section{REFERENCES}

[1] M. L. Williams, "Surface Stress Singularities Resulting from Various Boundary Conditions in Angular Corners of Plates under Bending," Proceedings, First U.S. National Congress of Applied Mechanics, ASME, June 1952, pp. 325-329.

[2] M. L. Williams, "Stress Singularities Resulting from Various Boundary Conditions in Angular Corners of Plates in Extension," Journal of Applied Mechanics, Transactions ASME, Vol. 19, No. 4, 1952, pp. 526-528.

[3] M. L. Williams, “On the Stress at the Base of a Stationary Crack," Journal of Applied Mechanics, Transactions ASME, Vol. 24, 1957, pp. 109-114.

[4] M. L. Williams, "The Stresses Around a Fault or Crack in Dissimilar Media,” Bulletin of the Seismological Society of America, Vol. 49, No. 2, 1959, pp. 199-204.

[5] A. R. Zak and M. L. Williams, "Crack Point Stress Singularities at a Bi-Material Interface,” Journal of Applied Mechanics, Vol. 30, 1963, pp. 142-143.

[6] J. W. Dally and T. Kobayashi, "Crack Arrest in Duplex Specimens," International Journal of Solids and Structures, Vol. 14, No. 2, 1978, pp. 121-126. doi:10.1016/0020-7683(78)90048-3

[7] P. S. Theocaris and J. Milios, "Crack Propagation Velocities in Bi-Phase Plates under Static and Dynamic Loading," Engineering Fracture Mechanics, Vol. 13, 1979, pp. 559-609.

[8] P. S. Theocaris and J. Milios, "Dynamic Crack Propagation in Composites," International Journal of Fracture, Vol. 16, No. 1, 1980, pp. 31-51. doi:10.1007/BF00042384

[9] P. S. Theocaris, "The Mesophase Concept in Composites,” Springer-Verlag, Berlin Heidelberg, 1987.
[10] P. S. Theocaris and J. Milios, "Crack Arrest at a Bimaterial Interface,” International Journal of Solids and Structures, Vol. 17, No. 2, 1981, pp. 217-230. doi:10.1016/0020-7683(81)90077-9

[11] P. S. Theocaris, M. Siarova and G. A. Papadopoulos, "Crack Propagation and Bifurcation in Fibber-Composite Models: I Soft-Hard-Soft Sequence of Phases," Journal of Reinforced Plastics and Composites, Vol. 5, No. 1, 1986, pp. 23-50. doi:10.1177/073168448600500104

[12] P. S. Theocaris and G. A. Papadopoulos, "Crack Propagation and Bifurcation in Fibber-Composite Models II: Hard-Soft-Hard Sequence of Phases," Journal of Reinforced Plastics and Composites, Vol. 5, No. 2, 1986, pp. 120-140. doi:10.1177/073168448600500204

[13] E. E. Gdoutos, "Failure of a Bimaterial Plate with a Crack at an Arbitrary Angle to the Interface," Fibber Science and Technology, Vol. 15, No. 1, 1981, pp. 27-40. doi:10.1016/0015-0568(81)90029-4

[14] E. E. Gdoutos and A. Giannakopoulou, "Stress and Failure Analysis of Brittle Matrix Composites, Part I: Stress Analysis,” International Journal of Fracture, Vol. 98, No. 3-4, 1999, pp. 263-277. doi:10.1023/A:1018354300645

[15] E. E. Gdoutos, A. Giannakopoulou and D. A. Zacharopoulos, "Stress and Failure Analysis of Brittle Matrix Composites. Part II: Failure Analysis," International Journal of Fracture, Vol. 98, No. 3-4, 1999, pp. 279-291. doi:10.1023/A:1018386616575

[16] E. N. Theotokoglou, G. J. Tsamasphyros and C. P. Spyropoulos, "Photoelastic Study of a Crack Approaching the Bonded Half-Plates Interface," Engineering Fracture Mechanics, Vol. 34, No. 1, 1989, pp. 31-42. doi:10.1016/0013-7944(89)90240-3

[17] C. P. Spyropoulos, E. N. Theotokoglou and G. J. Tsamasphyros, "Evaluation of the Stress Intensity Factors for a Crack Approaching the Bonded Half-plates Interface from Isopachics," Acta Mechanica, Vol. 81, No. 1-2, 1990, pp. 75-89. doi:10.1007/BF01174557

[18] G. A. Papadopoulos, "Crack-Tip Caustics at a Bi-Material Interface,” International journal of Fracture, Vol. 98, No. 1-2, No. 3-4, 1999, pp. 329-342. doi:10.1023/A:1018617719180

[19] L. Marsavina and T. Sadowski, "Stress Intensity Factor for an Interface Kinked Crack in a Bi-Material Plate Loading Normal to the Interface," International journal of Fracture, Vol. 145, No. 3, 2007, pp. 22-43. doi:10.1007/s10704-007-9124-z

[20] L. Marsavina and T. Sadowski, "Effect of Biaxial Load on Crack Deflection Penetration at Bi-Material Ceramic Interface," International journal of Fracture, Vol. 148, No. 1, 2007, pp. 79-84. doi:10.1007/s10704-008-9181-y

[21] M. M. Frocht, "Photoelasticity,” John Willey, New York, 1948.

[22] G. A. Papadopoulos, "Fracture Mechanics. The Experimental Method of Caustics and the Det-Criterion of Fracture,” Springer-Verlag, London, 1993. 